Г. С. Иваненко

Челябинск, Россия

ЛЕКСИКОГРАФИЯ И ЛИНГВИСТИЧЕСКАЯ ЭКСПЕРТИЗА: ПЕРСПЕКТИВЫ ВЗАИМООТНОШЕНИЙ

B статье рассматриваются перспективь взаимоотношений между двумя направлениями лингвистики: лексикографией и лингвистической экспертизой. Исследуется взаимодействие и взаимовлияние названных дисииплин в плоскости семантического анализа: лингвоэкспертология обозначает точки максимального интерпретационного напряжения, выявляет отдельные слова и типологические группь лексем, требующих разработки лексикографией. Лингвистическая экспертиза - заказчик лексикографического продукта, его пользователь, катализатор проблемных ситуаций, экспликатор нерешенных лексикографией вопросов, посредник между речевой практикой и лексикографическим описанием языка. Лексикография - производитель лесикографического продукта, обработчик информации, классификатор и квалификатор, посредник между языковой системой и ее пользователем - лингвоэкспертологией.

Выделяется три запроса лингвоэкспертологии к лексикографии: 1) уточнение, корректировка значений давно известных языку слов; 2) определение семантического объема и дифференциаџия значений новых слов; 3) описание значений слов в составе устойчивых семантико-грамматических конструкций.

В статье показывается, как в конкретных экспертных ситуациях оказывается недостаточно описаний давно известных языку слов. Многие описания не меняются за всю историю существования русской лексикографии, в то время как язык меняется, и динамические процессы в области семантических отношений требуют корректировки дефиниций. Не меньшего внимания лексикографии требуют к себе слова, появившиеся в языке в последние годы и вызывающие в экспертной практике конфликт интерпретащий. Также выделяется такая единица толкования, как лексико-грамматическая конструкиия, значение слова в которой имеет специфическую семантику, требующую описания.

Настоящий материал нацелен не только на обозначение болевых точек лингвистической экспертизы, в которых практическое направление лингвистики ищет поддержки у лексикографии, но и на побуждение лингвистического сообщества к созданию некоего банка спорных толкований, потенциально способного стать источником трансформащии / конкретизащии лексикографических описаний. 
Ключевые слова: лингвистическая экспертиза, лексикография, семантика, интерпретация.

Сведения об авторе: Галина Сергеевна Иваненко, дочент кафедры русского языка и методики обучения русскому языку Южно-Уральского государственного гуманитарнопедагогического университета. 454080, Челябинск, пр-m Ленина, 69. E-mail: gala.april@mail.ru

G. S. Ivanenko

Chelyabinsk, Russia

\section{LEXICOGRAPHY AND LINGUISTIC EXPERTISE: PROSPECTS OF MUTUAL}

\section{RELATIONS}

The article discusses the prospects of the relationship between the two areas of linguistics: lexicography and linguistic expertise. It explores the interaction and mutual influence of these disciplines in the plane of semantic analysis: linguotextology indicates the point of maximum interpretive tension, identifies individual words and typological groups of tokens that require the development of lexicography. Linguistic expertise is a customer of lexicographical product, its user, catalyst of problem situations, explicator of unsolved lexicographical questions, mediator between speech practice and lexicographical description of language. Lexicography is a manufacturer of lexicographical product, information processor, classifier, and qualifier, the mediator between the linguistic system and its user - linguotextology.

There are three demands of linguoexpertology to lexicography: 1) clarification, correction of the meanings of long-known words; 2) definition of semantic volume and differentiation of the meanings of new words; 3) description of the meanings of words as part of stable semantic and grammatical structures.

The article shows how specific expert situations lack descriptions of long-known words of the language. Many descriptions have not changed during the whole history of Russian lexicography, while the language is changing, and dynamic processes in the field of semantic relations require correction of definitions. No less attention is required to lexicography of words that have appeared in the language in recent years and cause a conflict of interpretations in expert practice. Also a unit of interpretation is introduced as a lexical-grammatical construction, the meaning of which has a specific semantics that require description.

This material is aimed not only at identifying the weak points of linguistic expertise, where applied linguistics is looking for support in lexicography, but also to encourage the linguistic community to create a Bank of controversial interpretations, potentially able to become a source of transformation / specification of lexicographical descriptions. 
Key words: linguistic expertise, lexicography, semantics, interpretation.

About the author: Galina Sergeevna. Ivanenko, Associate Professor of the Department of Russian Language and Methods of Teaching Russian, South Ural State University of Humanities and Education.454080,Chelyabinsk,Lenin Avenue,69.E-mail: gala.april@mail.ru

DOI 10.14258leglin(2018)7-810

Опыт производства лингвистических экспертиз свидетельствует о неизбежности использования лингвистом-экспертом результатов лексикографического труда. Редкая экспертиза не содержит ссылок на данные словарей. Обращение к словарям обусловлено потребностью установить спектр значений слова, значимые для результатов исследования оттенки семантики лексемы, стилистическую окраску. Далеко не всегда, в силу активных динамических процессов в области лексики, словари содержат актуальную информацию [Крысин 2008: 109]. Эксперты нередко вынуждены делать самостоятельные выводы, основываясь на анализе языкового материала, на результатах обработки данных Национального корпуса русского языка, на обращении к сведениям из монографий, статей по теме исследования. Однако выводы эксперта, не поддержанные данными словарей, вполне обоснованно воспринимаются участниками судебного процесса с некоторым недоверием. Именно словари имеют в общественном мнении статус надежных источников верифицированной информации о семантике и стилистике слова, что в целом представляется вполне объективным. Хотя, конечно, выбор значения слова из представленных в словаре согласно условиям контекста - процедура уже творческая, нередко становящаяся источником конфликта интерпретаций. Нередко лингвист-эксперт вынужден заявлять о не зафиксированном словарями значении, об изменении стилистики слова в современной языковой ситуации. Выводы отдельного исследователя по частному вопросу могут быть в различной степени значимы для формирования общеязыковой картины, однако, независимо от успешности отдельных трактовок, важно осознать наметившуюся межпредметную связь: лингвистическая экспертиза как 
практическая область реализации лингвистического знания может послужить лексикографии своеобразным индикатором проблемных сфер.

Любые взаимоотношения предполагают двунаправленные, взаимообратные векторы интереса, воздействия, влияния. Являются ли отношения лингвистической экспертизы и лексикографии взаимными и могут ли они быть таковыми? Чем одно направление лингвистики может помочь другому? Представляем взаимодействие лингвоэкспертологии и лексикографии, каким оно видится, в таблице № 1.

Таблица № 1. Взаимодействие лексикографии и лингвистической экспертизы

\begin{tabular}{|c|c|}
\hline Лингвистическая экспертиза & Лексикография \\
\hline лексикографического & $\begin{array}{l}\text { Исполнитель лексикографического } \\
\text { продукта }\end{array}$ \\
\hline Пользователь & Создатель, производитель \\
\hline $\begin{array}{l}\text { Катализатор проблемных ситуаций, } \\
\text { экспликатор } \\
\text { лерешенных } \\
\text { лексикографией вопросов }\end{array}$ & $\begin{array}{l}\text { Обработчик информации, } \\
\text { классификатор и квалификатор }\end{array}$ \\
\hline $\begin{array}{l}\text { Посредник } \\
\text { практикой и } \quad \text { лексикографическим } \\
\text { описанием языка }\end{array}$ & $\begin{array}{l}\text { Посредник } \text { между языковой } \\
\text { системой и еe пользователем - } \\
\text { лингвоэкспертологией }\end{array}$ \\
\hline
\end{tabular}

Естественным образом существующее межпредметное взаимодействие может иметь своим результатом как продуктивное решение рабочих проблем, так и нарушение границ компетенции. Поэтому рассмотрение точек междисциплинарного контакта, направлений и характера такого взаимодействия способно активизировать практически значимые направления исследований. Анализ лингвоэкспертной практики в аспекте обращения к лексикографическим источникам позволил выделить в настоящем материале три связанные позиции, по которым лингвистическая экспертиза создает запрос 
лексикографии. Очевидно, количество таких позиций большее, например, многие говорят о востребованности обновленных стилистических помет [Голев 2002]. Востребованы словари инвективной и ненормативной лексики [Бельчиков 2002; 2003], хотя нерешенный вопрос о соотношении статичных и динамичных составляющих стилистической характеристики слова затрудняет решение этой задачи.

Обратимся здесь к тем аспектам, материал для которых дали конкретные судебные разбирательства. Описание судебной коллизии помогает понять лингвистическую нишу вопроса и спроецировать экспертные вопросы практического характера на теорию лексикографии. Ограничимся также вопросами собственно семантического характера. Выделим три запроса лингвоэкспертологии к лексикографии:

1) уточнение, корректировка значений давно известных языку слов;

2) определение семантического объема и дифференциация значений новых слов;

3) описание значений слов в составе устойчивых семантикограмматических конструкций.

Рассмотрим репрезентирующие эти ниши три ситуации, в которых для решения правового конфликта потребовалось привлечение лингвистики, а именно лексикографии.

\section{І. Уточнение, корректировка значений давно известных языку слов.}

Проиллюстрируем проблему описанием правового и лингвистического конфликта, связанного с трактовкой семантики слова продольный. Понятие это оказалось в центре спора о тождестве / различии изобретений, рассматриваемых в суде по их патентным описаниям. Вопрос к патентоведу: «Свидетельствуют ли описания патентов об одинаковых изобретениях или о различных?» - оказался, как выяснилось в ходе разбирательства, лингвистическим.

Патент № 1: Канал для цุиркуляцчии бурового раствора выполнен под углом к образующей поверхности посадочного конуса корпуса от 10 до 55 градусов. 
Патент № 2: Каналь посадочного конуса внутреннего корпуса выполнены продольными по отношению к образующей поверхности посадочного корпуса.

Эксперт-патентовед так ответил на вопрос:

«Общепринятое значение понятия «продольный» понимается как проходящฺй по направлению длины, расположенный по длине чего-либо [Кузнецьов 1998; Евгеньева 1999; Ефремова 2001]. Значение данного словесного элемента [продольный] не требует строгой параллельности каналов $u$ образующей корпуса и допускает отклонение от продольной оси корпуса. Исходя из данного смысла, выполнение пазов изделия в полном соответствии с Документащией и Паспортом под углом в 10-55 градусов к образующей наружной поверхности внутреннего корпуса соответствует признаку формуль, предполагающей ориентацчию каналов по направлению длиньл образующей поверхности корпуса (то есть продольно)» [БорщзКомпанеец 2010].

Вопросы лингвистического характера, связанные с раскрытием семантики понятия продольнылй:

- Может ли «расположенный под углом» быть назван «продольно расположенным»?

• Предполагает ли понятие продольнылй расположение под углом к оси?

- Совместимы ли применительно к одному и тому же объекту характеристики «расположенный под углом» и «продольный»?

Как следует из процитированного ответа, патентоведом была представленная следующая позиция:

- «Расположенный под углом» может быть назван «продольно расположеннымм».

- Понятие продольный допускает расположение под углом к оси 10-55 градусов.

- Применительно $к$ одному и тому же объекту допустимы характеристики «расположсенный под углом» $и$ «рродольный». 
Для выяснения соотнесения двух понятий применяем лексикосемантический анализ. Оттолкнемся от значений, представленных в толковых словарях, начав с первого, в котором слово зафиксировано - словаря В. И. Даля.

ПРОДОЛЬНЫЙ, вдольный, что идет, лежит вдоль, по длине, длинником, противопол. поперечный. Продольная настилка, длиной досок или пластин по длине застилаемого протяжения; поперечная, длиной досок, в ширину дороги, полосы. Продольный разрез здания, в чертеже. Продольные выстрелы, - огонь, по длине расположения стана, войска, укреплений. Продоль ж. сиб. вдоль, долью, по длине. Продоль воды, по течению. || Всякая вдольная настилка [Даль, 1978].

ПРОДОЛЬНЫЙ, продольная, продольное. Проходящий по направлению длины или расположенный по длине чего-нибудь, ант. поперечный. Продольный разрез машины (на чертеже). Продольная распилка. Продольная сторона здания. Продольная пила (для распилки дерева вдоль, напр. бревна на доски) [Ушаков 1940].

ПРОДОЛЬНЫЙ - Расположенный по длине, вдоль чего-нибудь [Ожегов, Шведова, 2006].

Продольный, - ая, - о е Расположенный в длину, вдоль чеголибо, проходящий по долевому направлению (противопол.: поперечный). На самой вершине голой скалы возвышалась четырехугольная башня, вся черная, еще крепкая, но словно разрубленная продольной трещиной. Тург. Ася, 4. Сядешь на эту софу, и какая бы качка ни была - килевая ли, то есть продольная, или боковая, поперечная - упасть было некуда. Гонч.Фрег. «Паллада〉, I, 2. Все корабли начали стрелять по самому хребту, простреливая его продольным огнем. Степан. Порт-Артур, I, 2. о Продольная пила. Служащая для распиловки древесины вдоль. Быланин тоже никогда не разводил продольной пилы, но видел, как делали это другие. Наседк. Болып. семья, I, 19. => В слож. В названиях станков. Продольно-фрезерный станок. 
Продольно-распиловочный станок. Продольно-строгальный станок. - Слов. Акад. 1822: продольный [ССРЛЯ 1961, т. 11: 1045].

ПРОДОЛЬНЫЙ прил. Расположенный в длину, вдоль чего-л., проходящий по долевому направлению (противоп.: поперечный) [Ефремова 2000].

Из приведенных описаний следует, что за 150 лет толкование слова существенно не изменилось. В лексикографических описаниях использованы следующие интерпретирующие характеристики понятия продольный:

• расположенный в длину, по длине;

• проходящий по направлению длины;

• расположенный по долевому направлению, вдоль чего-либо.

Выделяем мотивирующие толкование элементы. Как следует из непротиворечивых лексикографических описаний, слово «продольный» толкуется через комплекс мотиваторов (используем это понятие для обозначения языковых средств истолкования значения): 1) расположенный в длину, по длине; 2) проходящий по направлению длины; 3) расположенный по долевому направлению, вдоль чего-либо. Раскрываем мотиваторы.

Расположенный по длине:

ДЛИНА́ ж. протяжение вдоль, доли́на; пск. долица, должина, твер. пск. длинь, перм. доль; за длину пространства, тела или вещи обычно берется направление наибольшего протяжения его; длина, ширина и вышина, или мера по уровню вдоль и поперек и мера по отвесу, составляют три основные протяжения всякого тела или пространства [Даль 1978].

Как видим, важным элементом толкования слова является семантический компонент «направление». Оно употребляется и в собственно толкованиях прилагательного «продольный», и в толковании его мотиватора «длина» (по длине).

Мотиватор «вдоль» также приводит к понятию «направление»:

ВДОЛЬ - 1)В направлении длины чего-нибудь. 2) В продольном направлении, по длине [Ефремова 2000]. 
ВДОЛЬ - 1. предлог в соединении с «по» с дат. или без него с род. По направлению длины чего-нибудь. Вдоль стены стоят книжные полки. Вдоль берега. Вдоль по берегу. 2. Тоже в знач. нареч. Разрезать материю вдоль. Вдоль и поперек (разг.) - 1) во всех направлениях. Изъездил Европу вдоль и поперек. 2) перен. совершенно, вполне, во всех подробностях. Я изучил эту книгу вдоль и поперек [Ушаков 1940].

Таким образом, понятие «продольный» жестко связано с понятием «направление». Все мотиваторы сходятся в этой семантической точке.

НАПРАВЛЕНИЕ 1.Процесс действия по знач. глаг.: направлять, направить. 2. Линия движения в какую-л. сторону, к какому-л. месту. 3. Путь развития, политическое, научное течение [Ефремова 2000]. Соединив раскрытые мотиваторы, получим уточненное определение:

ПРОДОЛЬНЫЙ - расположенный по направлению линии наибольшей протяженности предмета.

Понятия «направления» и «линия» предполагают определенность направления и его заданность (!). То, что расположено продольно, находится именно вдоль линии наибольшей протяженности предмета, и ни в каком другом направлении. Совершенно очевидно, что расположение под углом к какой-либо линии не может считаться расположенным вдоль этой линии. Ни о какой тождественности понятий речь идти не может. Это следует уже из результатов раскрытия значения слова через мотиваторы.

Убедительным дополнительным доказательством сказанного является реализация третьего этапа лексико-семантического метода: включения слова «продольный» в систему семантических отношений. Подбор синонимов и антонимов полностью разбивает мнение о том, что расположенность под углом - разновидность продольного расположения.

Антонимом к слову «продольный» является слово «поперечный».

ПОПЕР'ЕЧНЫЙ, поперечная, поперечное. Пересекающий что-нибудь поперек, расположенный поперек чего-нибудь; ант. продольный. Поперечная линия. Отверстие в виде поперечной щели. Поперечное положение ребенка при 
родах. Поперечное сечение. Поперечная пила (режущая дерево поперек его волокон). Встречный и поперечный - см. встречный. Поперечная мука (спец.) - обыкновенная ржаная мука, с отрубями, не отсеянная [Ушаков 1940].

Для решения рассматриваемой проблемы сам факт наличия антонима имеет решающее значение. Известно, что не все слова имеют антонимы. Слово с противоположным значением отсутствует у тех слов, которые обозначают что-то неконкретное, не имеющее критериев соотнесения с объектом действительности. Наличие антонима означает, что существуют критерии соотнесения слова с объектом реальности. В рассматриваемом случае конкретность очевидна, и она может быть передана специальными терминами.

Стилистически нейтральные понятия продольный и поперечный имеют синонимические терминологические обозначения параллельный и перпендикулярный.

Продольный - параллельный линии наибольшего протяжения предмета. Поперечный - перпендикулярный линии наибольшего протяжения предмета.

Используем включение лексемы в семантические отношения: каким словом можно будет обозначить то, что расположено по отношению к оси под углом 45 градусов? Оно будет продольным или поперечным? Ответ на вопрос невозможен, поскольку продольный и поперечный, как и их синонимы параллельный и перпендикулярный - строгие понятия, четко обозначающие направление расположения объекта в пространстве относительно оси.

Суждение о возможной нестрогой параллельности продольно расположенного объекта вызвано неразличением собственно значения слова и его смысла в контексте. Значение - константная категория, смысл ситуативная.

Само значение слова «продольный», как и «параллельный», предполагает совершенно определенное направление расположения объекта вдоль оси. Строгость же понимания этой параллельности (продольности) зависит от стиля текста и его содержания. В художественном, разговорном, публицистическом стиле все слова реализуют более широкий спектр смыслов, в официально- 
деловом и научном тексте значения фиксированы и строги. Покажем это на примерах: (1) Они шли параллельно дороге. (2) Они или вдоль дороги.

Смысл двух предложений идентичен. Ни у кого не вызывает сомнений строгость и четкость понятия параллельный, однако в данном контексте «параллельно», как и «вдоль», допускает движение идущих с некоторыми отклонениями от прямой линии с сохранением в целом направления. Но если бы идущие двигались под углом к дороге, их движение нельзя было бы назвать ни параллельным дороге, ни направленным вдоль нее.

То же самое и применительно к слову «продольный». Конечно, в повести И. С. Тургенева «Ася» не предполагается абсолютная параллельность линий: «...четырехугольная башня, вся черная, ещче крепкая, но словно разрубленная продольной трещуиной» (цит. по: [ССРЛЯ 1961, т. 11: 1045]). В контексте же точных дисциплин продольность не предполагает каких-либо отклонений от строго определенного направления: ПРОДОЛЬНАЯ ОСЬ бруса, автомобиля, самолета.

В ситуациях, связанных с изготовлением конкретных изделий, текстовые описания предполагают выражение смысла, строго соответствующего четким критериям. Так, если при пошиве изделия требуется сделать продольный разрез, то отступления от строгой параллельности недопустимы. Изделие, выполненное с разрезом от 10 до 55 градусов от оси, будет испорченным. Продольная распиловка бруса или доски также не допускает непараллельности. Данный признак (параллельность) должен быть соблюден обязательно.

В рассматриваемой судебной ситуации о патентовании изобретения речь также идет о конкретном изделии, выполняемом по конкретному чертежу. В контексте описания технических характеристик изделия никакая вольность трактовок недопустима.

Таким образом, очевидно, что определение «продольный» подразумевает «расположенный параллельно длине». В контекстах, не предполагающих скрупулезной точности в описании расположения предметов, речь может идти о нестрогой параллельности, то есть о параллельности, высчитанной не с 
математической точностью, а воспринятой приблизительно, на глаз, на обозримом отрезке. Однако даже при таком нестрогом понимании «продольный» и «расположенный под углом» - совершенно разные понятия. Понятие «продольный» не предполагает расположение предметов под углом.

В результате лингвоэкспертного рассмотрения в рамках правового конфликта было выявлено, что в современной речевой ситуации слово продольный отодвинуто на второй план более востребованным синонимом параллельныци, несколько изменило нишу употребления и в связи с этим обстоятельством нуждается в уточнении. Лексикографии для дальнейшей работы передается сырой материал:

Продольный: 1) расположенный вдоль линии наибольшей протяженности (продольная трещина) - не предполагает строгой параллельности, объекты параллельны на видимом отрезке; 2) сnеu. Параллельный (продольная распиловка бруса, продольный разрез, продольное расположение деталей).

По итогам рассмотрения семантики слова продольный и динамики его семантических отношений в современной лексике можно сказать, что экспертная практика может обозначать лексикографии проблемные сферы, казалось бы, устоявшихся толкований.

II. Описание семантического объема и дифференциация значений нового для языка слова - вторая выявленная ниша взаимодействия лексикографии и лингвоэкспертологии. Проиллюстрируем эту проблемную ситуацию конфликтной интерпретацией слова Интернет.

Предметом лингвоэкспертного рассмотрения стал п. 2, подпункт д) ст. 110 УК РФ «То же деяние, сопряженное с публичным выступлением, использованием публично демонстрирующегося произведения, средств массовой информацчии или информационно-телекоммуникацчионных сетей (включая сеть “Интернет”),...».

То есть деяние оценивается как более тяжкое, если при его совершении были использованы указанные средства. В рамках дел, возбужденных по настоящей статье, стали возникать следующие коллизии: как квалифицировать 
использование сети Интернет не в качестве средства распространения информации, а в качестве технического средства связи (общение по скайпу, в социальной сети, ICQ, Телеграм, Viber, др.)? Мнение обвинения и защиты по этому вопросу не совпадает. Принципиальную роль для интерпретации текста закона и соотнесения с денотатом дала бы полная, исчерпывающая, актуальная дефиниция лексемы «Интернет».

Отсутствие дифференциации значений слова Интернет в словарях становится основанием привлечения по ст. 110, а наличие дифференциации позволяет доказать несоответствие квалификации деяния запретительной норме.

Лингвистические вопросы в рамках правового конфликта:

- Каково значение слова Интернет в современном русском языке? в настоящем контексте?

- Интернет в контексте ст. 110 УК РФ - способ распространения информации или средство ее передачи, то есть информационный ресурс или техническое средство?

Для ответа на вопросы необходимо обратиться к лексикографическим описаниям. Их было найдено немного.

ИНТЕРНЕТ (англ. Internet от лат. inter - между и англ. net - сеть паутина), международная (всемирная) компьютерная сеть электронной связи, объединяющая региональные, национальные, локальные и др. сети. Способствует значительному увеличению и улучшению обмена информацией, прежде всего научно-технической. Объединяет свыше 50 млн. коллективных и индивидуальных пользователей (каждый со своим электронным адресом) во всем мире [БЭС 2000].

ИНТЕРНЕТ - всемирная компьютерная сеть, позволяющая пользователям персональных компьютеров, находясь в любой точке земного шара, иметь связь друг с другом, получать и передавать информацию [Новый словарь иностранных слов 2009]. 
Слово Интернет еще очень молодо, но уже успело пройти определенный путь развития в нашем языке. Сначала обозначало конкретную информационную компьютерную сеть, в связи с чем закрепилось приоритетное написание с заглавной буквы. Затем значение слова как имени собственного стерлось, на первый план вышло нарицательное значение, указывающее на определенное средство коммуникации.

Описания значения слова Интернет не коррелируют с картиной, выявленной по результатам анализа употреблений лексемы в реальных контекстах.

Анализ значения слова по различным источникам показал, что слово Интернет используется в двух значениях:

1) информационный ресурс, то есть средство распространения и получения информации: Эта проблема с ещуе большими последствиями возникает при поиске информацчии в сети Интернет, которая стала поистине всемирным хранилищем и распространителем разнотипных информациинных документов [Керимов 2004].

2) Техническое средство связи, то есть способ передачи информации: $A$ платеж можно сделать не только в отделении банка, но и через телефон, Интернет [Крашаков 2003].

Оформим различия между значениями слова Интернет в виде таблицы

Таблица № 2. Значения слова Интернет.

\begin{tabular}{|l|l|l|}
\hline ИНТЕРНЕТ & Значение № 1 & Значение № 2 \\
\hline Значение & $\begin{array}{l}\text { информационный } \\
\text { ресурс }\end{array}$ & $\begin{array}{l}\text { техническое средство } \\
\text { связи }\end{array}$ \\
\hline Расшифровка & источник сведений \\
различного характера & $\begin{array}{l}\text { способ осуществить } \\
\text { какую-либо } \\
\text { операцию } \\
\text { расстоянии }\end{array}$ \\
\hline Сочетаемость & искать в Интернете & через Интернет \\
\hline
\end{tabular}




\begin{tabular}{|c|c|c|}
\hline & $\begin{array}{l}\text { найти в Интернете } \\
\text { распространить } \\
\text { Интернете }\end{array}$ & $\begin{array}{l}\text { посредством } \\
\text { Интернета }\end{array}$ \\
\hline Аналоги по функции & $\begin{array}{l}\text { Книги, СМИ, радио, } \\
\text { телевидение, } \\
\text { публичное } \\
\text { выступление }\end{array}$ & $\begin{array}{l}\text { Почта, } \\
\text { телефолеграф, } \\
\text { разговор, СМС }\end{array}$ \\
\hline Функционирование & $\begin{array}{l}\text { Накопление } \\
\text { распространение } \\
\text { информации } \\
\text { неопределенному } \\
\text { кругу лиц }\end{array}$ & $\begin{array}{l}\text { Передача } \\
\text { конкретного сведения } \\
\text { по конкретному } \\
\text { вопросу конкретному } \\
\text { адресату }\end{array}$ \\
\hline $\begin{array}{l}\text { Отношение } \\
\text { публичности }\end{array}$ & $\begin{array}{l}\text { средство реализации } \\
\text { публичности }\end{array}$ & $\begin{array}{l}\text { Не имеет отношения } \\
\text { к публичности }\end{array}$ \\
\hline
\end{tabular}

В контексте статьи 110 УК РФ отдельным пунктом с особой ответственностью выделяется распространение информации в ПУБЛИЧНЫХ источниках. Именно публичность называется отягчающим фактором деяния. Поэтому совершенно очевидно, что сеть Интернет рассматривается в данном случае в значении №1 - как источник накопления, хранения и распространения информации. В контексте статьи 110 УК РФ Интернет представлен как один из информационных ресурсов: То же деяние, сопряженное с публичным выступлением, использованием публично демонстрирующееося произведения, средств массовой информации или информационно-телекоммуникационных сетей (включая сеть «Интернет»).

О том, что Интернет в контексте ст. 110 УК РФ обозначает информационный ресурс, а не технический способ связи, свидетельствуют факторы:

1. Выдвижение на первый план такой характеристики деяния, как публичность. 
2. Использование понятия сеть «Интернет» в скобках, в качестве указания на частный случай средства реализации публичности; Интернет как разновидность информационных сетей.

3. Упоминание Интернета в одном ряду со СМИ и информационнотелекоммуникационными сетями как средством распространения информации.

4. Отсутствие в одном ряду со словом Интернет других понятий, указывающих на конкретный технический способ распространения информации, например, таких, как СМС, телефон, телеграф.

Итак, Интернет в исследуемом контексте - не средство связи, а средство распространения информации. Различение приведенных двух значений влияет на квалификацию деяния. В контексте п. 2, подпункта (д) ст. 110 УК РФ Интернет - средство распространения информации неопределенно широкому кругу лиц, то есть средство придания информации публичности (значение 1). Поскольку именно распространение информации широкому кругу лиц является значимым в диспозиции ст. 110 УК РФ, то случай, когда Интернет стал техническим средством передачи сведений (как почта, телеграф, телефон) (значение 2), этой диспозиции не соответствует, и человек не понесет дополнительной ответственности.

Описанный конфликт интерпретаций убеждает в востребованности правовой системой, социумом актуальных лексикографических описаний лексем, возникших и/или распространившихся в языке в последние два десятилетия. Лингвоэкспертология способна обозначать лексикографии точки максимальной востребованности.

III. Описание значений слов в составе устойчивых семантикограмматических конструкций

Под семантико-грамматическими понимаем здесь конструкции, которые в рамках грамматической модели имеют частично фиксированный лексический состав и самостоятельное значение слова, отличное от значений этой же формальной оболочки в других структурах. Фразеологизмом такие 
конструкции назвать нельзя, так как два или более лексических компонента не утратили самостоятельной семантики и не приобрели целостной. В одном из судебных конфликтов в центре дискуссии оказалось значение конструкции «люди Иванова». В правовом аспекте разрешался вопрос: в каких отношениях находятся люди и Иванов? Люди Иванова, согласно тексту статьи, совершали недостойные поступки. Иванов настаивал на том, что эти люди с ним никак не связаны. Журналисты же утверждали, что в любом случае репутация Иванова не задета, так как люди Иванова - это не то же самое, что сам Иванов.

Словарное определение значения рассматриваемой конструкции выявлено при выражении второго компонента существительным неодушевленным, то есть люди чего:

Лица, принадлежащие к какой-либо общественной среде, группе; лица, объединяемые какими-либо общими признаками. Л ю д и чего. Люди науки, Каждый член общества призван делать свойственное ему дело. И люди мысли исполняют свое дело, выражая общественное мнение. Л. Толст. Анна Карен. - Я сам хотел бы причислить себя к людям искусства, служить искусству, потому что хотел бы воздействовать на людей. Федин, Необыкн. Лето [ССРЛЯ 1061, т. 6: 442].

Нетождественность интерпретаций вызвала модель с компонентомсуществительным в родительном падеже, выражающим семантикограмматическую категорию одушевленности, то есть люди кого. Очевидно, что в настоящем случае значима дифференциация одушевленность / неодушевленность компонента Ү.

Синтаксическая модель «люди кого-либо» использовалась и в XVI-XIX веках, обозначая непосредственную принадлежность людей их юридическому и фактическому хозяину. В рамках указанного значения люди, например, Дубровского - это его крепостные. На базе указанного значения развился метонимический перенос: рабы / крепостные в то же время являлись слугами, подчиненными. Модель «люди кого-либо» стала использоваться для обозначения зависимости социального / политического / военного характера 
(люди Ивана Грозного, люди Курбского, люди Марины Мнишек). Описанное значение так представлено в Большом академическом словаре:

4. В буржуазно-дворянском быту - лица, находящиеся в подчинении у кого-либо; слуги. - Моих людей не будет в доме: я им всем раздала билеты, также и людям княгини. Лерм. Кн. Мери. Еще не доезжая деревни, князь и люди его услышали веселые песни. А. К. Толст. Кн. Серебряный. Пошли мы, и господа, и люди, все вместе, - тут не было разбора. Герцен, Былое и думы» [ССРЛЯ 1961, т. 6: 443].

Выражение «люди кого-либо» в приведенном значении утратило актуальность в советский период по социально-политическим причинам. С момента создания словаря язык существенно изменился, но в других словарях, приближенных к нам по времени, значение конструкции не представлено.

В 90-е годы XX века конструкция получила новую жизнь с распространением в криминальной среде (Люди Сидоренко требуют отдать им игорный бизнес), потом перешла в обыденную речь, а затем в публицистику и литературу.

Модель «люди кого-либо» активно употребляется и в современном русском языке. Слово в родительном падеже называет лицо, обладающее какими-либо полномочиям / возможностям: управленческими, материальными, административными, любыми иными. Кто-либо в данной модели - человек, управляющий другими людьми на каком - либо основании: как официальный начальник, как покупатель услуг, как манипулятор, опирающийся на физический, психологический, политический или иной pecypc.

Рассмотрение одной лексико-грамматической конструкции показало, что, во-первых, в рамках определенных моделей слова приобретают регулярные самостоятельные значения и нуждаются в фиксации, во-вторых, подобные модели, как и отдельные лексемы, подвержены семантической динамике, и втретьих, лингвоэкспертология способна накапливать для лексикографии опыт практической конфликтной интерпретации. 
Настоящий материал нацелен не только на обозначение болевых точек лингвистической экспертизы, в которых практическое направление лингвистики ищет поддержки у лексикографии, но и на побуждение лингвистического сообщества к созданию некоего банка спорных толкований, потенциально способного стать источником трансформации / конкретизации лексикографических описаний. В любом случае опыт взаимодействия двух направлений лингвистики не может быть бесплодным.

\section{ЛИТЕРАТУРА}

1. Бельчиков Ю. А. Инвективная лексика в контексте некоторых тенденций в русской речевой коммуникации. Филологические науки. 2002. № 4. С. 66-74.

2. Бельчиков Ю. А. Русский язык ХХ век. М., 2003. Гл. 1. С. 53-75.

3. Борщ-Компанееи Н. C. Заключение патентного поверенного. Материалы гражданского дела № 2-763/2010, Ленинский районный суд г. Челябинска.

4. Большой энциклопедический словарь. URL: https://dic.academic.ru/dic.nsf/enc3p/139894

5. Голев Н. Д. Об объективности и легитимности источников лингвистической экспертизы. Юрислингвистика-3. Барнаул, 2002.

6. Даль В. И. Толковый словарь живого великорусского языка. М., 2006.

7. Едремов B. A. Словари субстандатра в экспертной практике. Вестник Новосибирского государственного педагогического университета. 2015. № 2(24). С. 41-49.

8. Едремова T. Ф. Новый словарь русского языка. Толково-образовательный. В 2-х тт. M., 2000.

9. Крысин Л. П. Слово в современных текстах и словарях. Очерки о русской лексике и лексикографии. Нормативные словари как инструмент лингвистической экспертизы текста. M., 2008.

10. Кузнецов С. А. Большой толковый словарь русского языка Справочное издание. СПб., 2000.
11. Новый
словарь
иностранных
слов.
URL:

https://dic.academic.ru/dic.nsf/dic_fwords/1742

12. Ожегов С. И. Шведова Н. И. Словарь русского языка. М., 2006.

13. Словарь русского языка: В 4-х тт. / Под ред. А. П. Евгеньевой. М., 1999. Т. 1.

14. Словарь современного русского литературного языка в 17-ти тт. / Под общей редакцией Ф. П. Филина. М.-Л., 1961. 
15. Ушаков Д. Н. Толковый словарь русского языка. В $\quad$ 4-х $\quad$ тT. URL: https://dic.academic.ru/dic.nsf/ushakov/959062

\section{ИСТОЧНИКИ}

1. Керимов С. Г. Интеллектуальный поиск информации, основанный на онтологии. Информационные технологии, 2004 / Национальный корпус русского языка. URL: http://www.ruscorpora.ru/

2. Крашаков A. Иностранцы «съедают» наши банки? «Аргументы и факты», 2003.01.29 / Национальный корпус русского языка. URL: http://www.ruscorpora.ru/

\section{REFERENCES}

1. Belchikov Yu. A. Invective Vocabulary in the Context of Certain Trends in Russian Speech Communication [Invektivnaya leksika v kontekste nekotoryh tendencij v russkoj rechevoj kommunikacii]. Philological Sciences. 2002. № 4. Pp. 66-74.

2. Belchikov Yu. A. Russian language of the twentieth century [Russkij yazyk XX vek]. Moscow, 2003. Ch. 1. Pp. 53-75.

3. Borsch-Kompaneets N. S. Conclusion of the patent attorney. Materials of the civil case № 2-763 / 2010, Leninsky district court of Chelyabinsk [Zaklyuchenie patentnogo poverennogo. Materialy grazhdanskogo dela № 2-763/2010, Leninskij rajonnyj sud g. Chelyabinska].

4. Large encyclopedic dictionary [Bol'shoj ehnciklopedicheskij slovar']. URL: https://dic.academic.ru/dic.nsf/enc3p/139894

5. Golev N. D. The objectivity and legitimacy of the sources of linguistic expertise [Ob ob"ektivnosti i legitimnosti istochnikov lingvisticheskoj ehkspertizy]. Jurilinguistics-3. Barnaul, 2002.

6. Dal V. I. Explanatory dictionary of the living great Russian language [Tolkovyj slovar' zhivogo velikorusskogo yazyka]. Moscow, 2006.

7. Efremov V. A. The substandard of the expert practice [Slovari substandatra v ehkspertnoj praktike]. Bulletin of the Novosibirsk state pedagogical university. 2015. № 2 (24). Pp. 41-49.

8. Efremova T. F. The new dictionary of the Russian language. Sensible-educational [Novyj slovar' russkogo yazyka. Tolkovo-obrazovatel'nyj]. Moscow, 2000.

9. Krysin L. P. Word in modern texts and dictionaries. Essays on Russian vocabulary and lexicography [Slovo v sovremennyh tekstah i slovaryah. Ocherki o russkoj leksike i leksikografii. Normativnye slovari kak instrument lingvisticheskoj ehkspertizy teksta]. Normative dictionaries as a tool of linguistic expertise of the text. Moscow, 2008. 
10. Kuznecov S. A. The dictionary of the Russian language reference edition [Bol'shoj tolkovyj slovar' russkogo yazyka Spravochnoe izdanie]. St. Petersburg, 2000.

11. New dictionary of foreign words [Novyj slovar' inostrannyh slov]. URL: https://dic.academic.ru/dic.nsf/dic_fwords/1742

12. Ozhegov S. I., Shvedova N. I. Dictionary of the Russian language [Slovar' russkogo yazyka]. Moscow, 2006.

13. Dictionary of the Russian language in 4 volumes [Slovar' russkogo yazyka: V 4-h tt. / Pod red. A. P. Evgen'evoj]. Moscow, 1999. Vol. 1.

14. Dictionary of the modern Russian literary language in 17 volumes. Under the General editorship of F. P. Filin [Slovar' sovremennogo russkogo literaturnogo yazyka v 17-ti tt. / Pod obshchej redakciej F. P. Filina]. Moscow-Leningrad, 1961.

15. Ushakov D. N. Explanatory dictionary of the Russian language [Tolkovyj slovar' russkogo yazyka. V 4-h tt.]. URL: https://dic.academic.ru/dic.nsf/ushakov/959062

16. Kerimov S. G. Intellectual information search based on ontology [Intellektual'nyj poisk informacii, osnovannyj na ontologii]. Information technologies, 2004 / national corpus of Russian language. URL: http://www.ruscorpora.ru/

17. Krashakov A. Foreigners «eat» our banks? [Inostrancy «s"edayut» nashi banki?]. «Arguments and facts», 2003.01.29 / national corpus of the Russian language. URL: http://www.ruscorpora.ru/ 